\title{
A revisional study of the Chinese species of Amphiops Erichson (Coleoptera, Hydrophilidae, Chaetarthriini)
}

\author{
J.I.A. Fenglong* \\ Institute of Entomology, Life Sciences School, Sun Yat-sen University, Guangdong, China \\ (Received 30 January 2013; accepted 10 September 2013; first published online 5 February 2014)
}

\begin{abstract}
A review of the genus Amphiops occurring in China is provided. A new species, Amphiops coelopunctatus sp. nov., is described from Hainan, China. Based on a study of the type material, Amphiops yunnanensis $\mathrm{Pu}, 1963$, is proposed as a junior synonym of Amphiops mirabilis Sharp, 1890. Amphiops pedestris Sharp, 1890 and Amphiops annamita Régimbart, 1903 are confirmed as synonyms of Amphiops mater Sharp, 1873. Amphiops coomani d'Orchymont, 1926 is reported from China for the first time. Amphiops globus Erichson, 1843, previously reported from Macau, is found to be a misidentification. An identification key to Chinese species of the genus is provided.
\end{abstract}

http://www.zoobank.org/urn:1sid:zoobank.org:pub:47C95EED-8B09-4BE0-A3357E8B7CB23FE7

Keywords: Amphiops; Hydrophilidae; new species; new synonym; new record; China

\section{Introduction}

Since the genus Amphiops was erected by Erichson (1843), a total of 20 species and four subspecies have been described from the Australian, Oriental and Afrotropical regions (Hansen 1999; Short and Hebauer 2006; Short and Fikáček 2011). Only four species reach the southern boundary of the Palaearctic region: Amphiops senegalensis (Castelnau 1840) and Amphiops phallicus d'Orchymont, 1936 reach North Africa and Israel, and Amphiops mater Sharp, 1873 and Amphiops mirabilis Sharp, 1890 reach north of the Yangtze river in China (Beijing and Shandong provinces). d'Orchymont (1941) and Hebauer (1998) reviewed all species of the Afrotropical region and Watts (1998) reviewed the Australian fauna. Only the Oriental species have not been reviewed.

The first species from China, Amphiops mirabilis, was reported by d'Orchymont (1922) from Tsing tau (Qingdao), Shandong Province. d'Orchymont (1935) and Wu (1937) recorded Amphiops annamita Régimbart, 1903, A.mater and Amphiops pedestris Sharp, 1890 from China, but omitted a previous record of A.mirabilis. Balfour-Browne (1939) treated A.pedestris and A.annamita as subspecies of A.mater. Pu (1963) described Amphiops yunnanensis Pu, 1963 from Xiao Mengla, Yunnan Province. Jia (1994) described Amphiops caristripus Jia, 1994 from Fujian. Jäch and Easton (1998) reported a common Afrotropical species Amphiops globus Erichson, 1843 from Macau. To sum up, five species of Amphiops have been recorded from China so far.

Here, I provide results of the revisional study on fauna of Chinese Amphiops Erichson.

*Email: 1ssjf1@mail.sysu.edu.cn 


\section{Material and methods}

The types of a new species and those of Amphiops yunnanensis were studied for this paper. The holotype and a paratype of the new species were dissected, with the genitalia placed in water-soluble dimethyl hydantoin formaldehyde resin (specimens in Sun Yat-sen University) or in alcohol-soluble Euparal resin (specimens in National Museum, Prague, Czech Republic), both pinned below the respective specimens. All photos of A. yunnanensis $\mathrm{Pu}$ were taken using a ZEISS Discovery.V12 compound microscope at the Chinese Academy of Sciences, Institute of Zoology, Beijing. Remaining habitus photographs were taken using an Axioskop 40 compound microscope. Photographs of genitalia were taken using an Olympus SZX7 stereomicroscope, and subsequently combined using Auto-Montage software. Complete label data are provided for type specimens. Examined specimens are deposited in the following collections:

ACH Paul Aston Collection, Hong Kong, China;

IZCAS Chinese Academy of Sciences, Institute of Zoology, Beijing, China;

NMPC National Museum, Prague, Czech Republic;

SYSU Entomological collection of Sun Yat-sen University, Guangzhou, China.

Only the depository of the specimens not deposited in SYSU is indicated in the Material examined sections of each species.

\section{Systematics}

\section{Amphiops Erichson, 1843}

Amphiops Erichson, 1843: 229. Type species: Hydrophilus gibbus Illiger (designation: Knisch 1924: 259).

= Cyprimorphus Fairmaire, 1873: 334. Type species: Cyprimorphus compressus Fairmaire (= Coelostoma senegalense Castelnau) (monotypy). - Syn.: Zaitzev, 1908: 399.

This genus is very easy to recognize by the combination of the following characters: body very strongly rounded and very strongly convex, almost semiglobular; eyes completely divided by a lateral canthus into dorsal and ventral parts; antennae eight-segmented; scutellum elongate; visible part of first abdominal ventrite short and without or with very short carina medially, without a fringe of long hairs or stiff setae, but with fine setae rising from the basal margin of ventrite; large part of first abdominal segment completely covered by metacoxae, with a pair of large cavities laterally and sharp carina medially; abdominal ventrites 2 to 5 covered by hyaline mass; fifth abdominal ventrite simply rounded; middle tibiae with fringes of swimming-hairs.

Amphiops coomani Orchymont, 1926

(Figures $1 \mathrm{~A}-\mathrm{F}$, and $5 \mathrm{~A}$ )

Amphiops coomani Orchymont, 1926d: 246. - Type locality: Vietnam, Tonkin, Lac

Tho near Hoa Binh. For complete synonymy see Hansen (1999).

Amphiops globus Erichson: Jäch and Easton, 1998: 45, misidentification. 
A
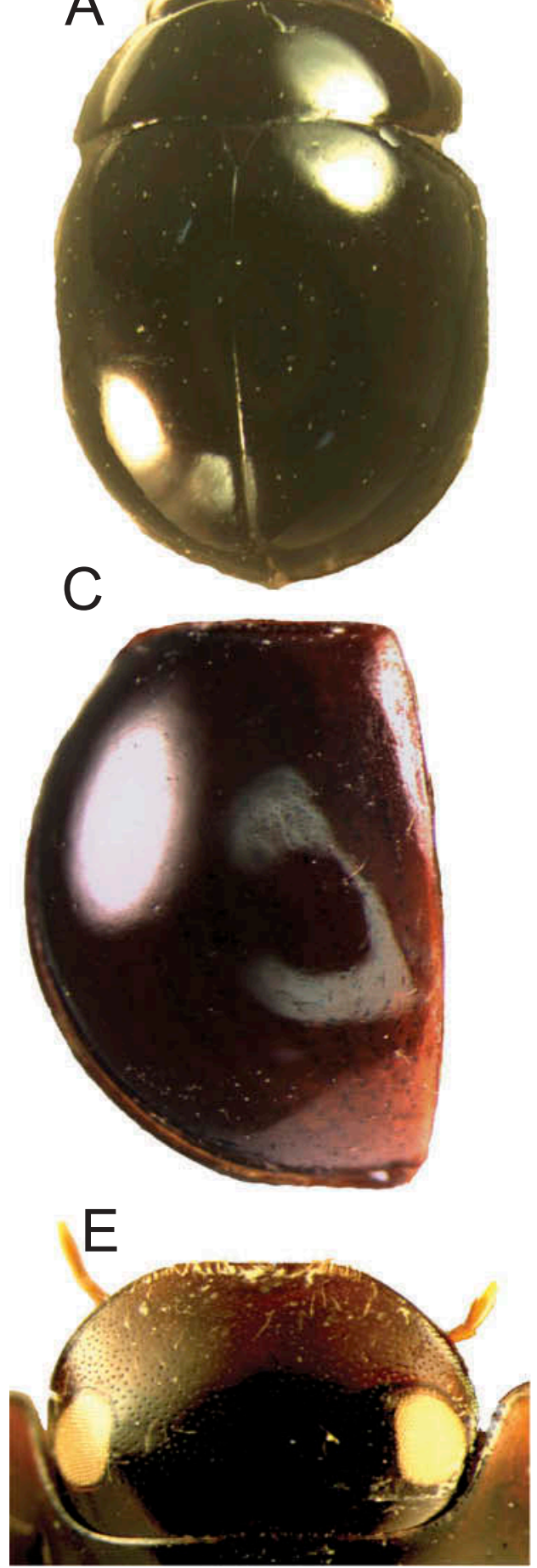

$\mathrm{B}$

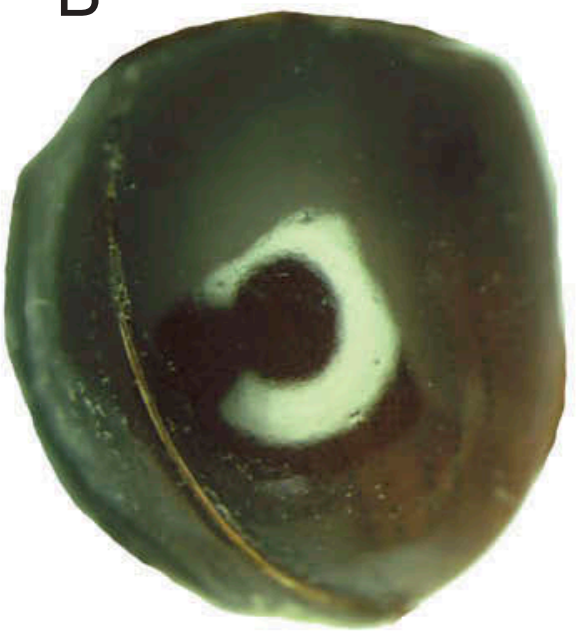

$\mathrm{D}$

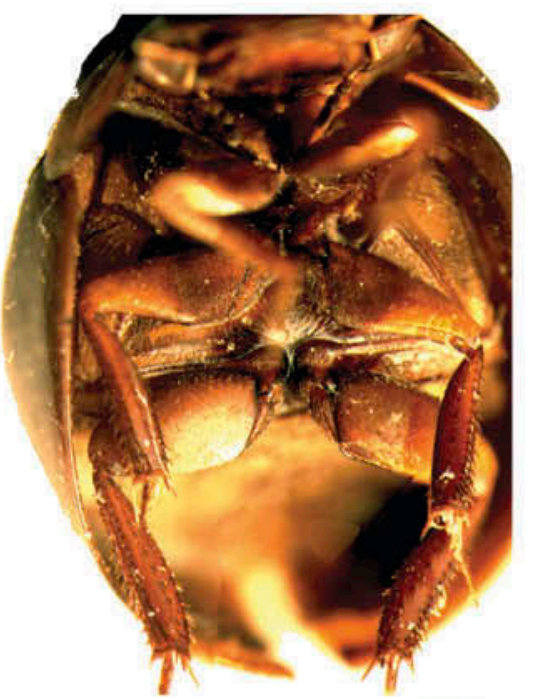

F

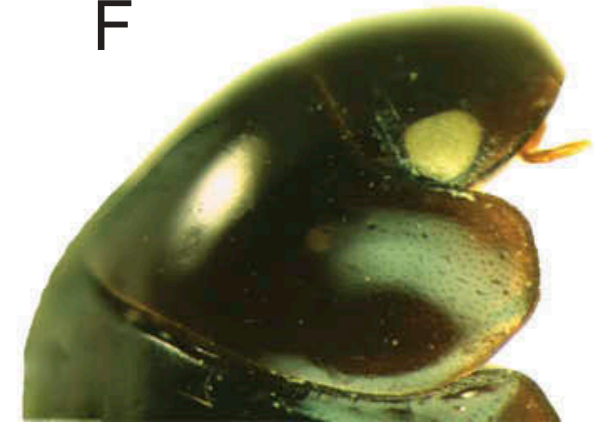

Figure 1. Amphiops coomani Orchymont. (A) Habitus; (B) elytra, dorsolateral view; (C) elytra, lateral view; (D) ventral surface; (E) head; (F) head and pronotum, lateral view. 


\section{Material examined}

CHINA: Guangdong: 3 male, 4 female and 5 unsexed spec., Shenzhen, 12-15 August 2006, Fenglong Jia leg.; 1 spec., Guangzhou, Luogang, 20 April 1956, Zhelong Pu leg. Hainan: 1 male and 2 unsexed spec., Jianfengling, 22 November 1983, Zhihe Huang leg.; Hong Kong: 2 males, 1 female, 2 December 2012, Wang Tang, Lantau, Paul Aston leg.; 1 female (ACH), same data as the former. Macau: 4 spec., Macau, 18 August 2012, Fenglong Jia leg. VIETNAM: 1 female, Tonkin, Hoa Binh, A. de Cooman leg.

\section{Differential diagnosis}

It is very easy to distinguish A.coomani from other species occurring in the Oriental region by pronotum and elytra with very fine punctures but with distinct coarse systematic punctures, lateroposterior margin of the pronotum strongly roundly curved forwards, resulting in the posterior angle being unclear, anterior margin of the metaventrite without transverse carina and mesocoxae narrowly separated. This species can be distinguished from the most similar species, the Afrotropical A.globus by mesofemora pubescent in basal half (only basal third is pubescent in A.globus), metafemora only pubescent anteriorly on basal half and not pubescent beneath (pubescent in basal one-fifth in A.globus), abdominal ventrites glabrous between setiferous punctures [ventrites with dense wrinkles in A.globus (d'Orchymont 1926)].

\section{Taxonomic notes}

When A.coomani was described by d'Orchymont (1926) based on two type specimens, the measurement given was " $3.6 \times 2.7$ millim". This is clearly smaller than the specimens examined by me. The size of these specimens is $3.8-4.2 \times 2.7-$ $2.8 \mathrm{~mm}$. I examined a specimen (length $4.0 \times 2.75 \mathrm{~mm}$ ) from Tonkin: Hoa Binh, Hoa Binh, leg. A. de Cooman deposited in SYSU that has the same characteristics as the specimens from China. Unfortunately the specimen from Tonkin is a female and the identification was therefore not confirmed by study of the aedeagus. However, as the type locality of A.coomani Orchymont is not far away from Hoa Binh, I am treating the specimen from Hoa Binh as A.coomani because it has all characters as described by d'Orchymont (1926). There is no doubt that the specimens from China and from Tonkin, Hoa Bihn examined for this study are conspecific.

Jäch and Easton (1998) reported A.globus, a very common Afrotropical species, from Macau, China. All specimens I examined from Macau belong to $A$. coomani which is very similar to A.globus, but clearly differs from it by several characters given above in the diagnosis. Amphiops coomani occurs not only in Vietnam, but also in Indonesia (Java, Sumatra) and South China. Hence, even though I have not had the chance to examine the specimens on which Jäch and Easton's (1998) based their record of A.globus, I consider their record as a misidentification of A.coomani. Amphiops globus is therefore excluded from the Chinese fauna. 


\section{Distribution}

China (Guangdong, Macau, Hainan), Indonesia (Java, Sumatra), Vietnam. New for Guangdong and Hainan.

Amphiops caristripus Jia, 1994

(Figure 2A-D)

Amphiops caristripus Jia, 1994: 100. - Type locality: China, Fujian province, Fuzhou.

\section{Material examined}

Holotype (SYSU), female: Fujian, Fuzhou, Xihu, 21 October 1963, Shanxiang Lin leg., with a red label "Holotype Amphiops caristripus, det. Fenglong Jia (in Chinese)", and another label "En-161623, Sun Yat-sen University, Biological Museum (transcript from Chinese)".

\section{Differential diagnosis}

This species differs from all other Chinese species by the very distinct frontoclypeal suture, pronotum with distinct wrinkles anteriorly, pronotum with smaller and less apparent systematic punctures than the species of the A.mater complex, elytra with five weak ridges on inner part, clearly striate laterally and apically, and outer five intervals distinctly elevated.

\section{Distribution}

China (Fujian). Known only from the type locality.

Amphiops coelopunctatus sp. nov.

(Figures 2E-J, and 5B)

Type locality

China, Hainan Island, Limushan Mountains, 550-750 m, 199.1-9.2' N, 10945-46' E

\section{Type material}

Holotype male (SYSU): China, Hainan island Limushan Mountains, 5 May 2011, 199.1-9.2' N, 10945-46' E, 550-750 m, Fikáček and Zhao lgt. Paratypes:1 male and 3 females (SYSU), same data as holotype; 1 male, 2 spec. (NMPC): China, Hainan island, Limushan Mountaint, 199.1-9.2' N, 1094546' E, 550-750 m, along the road, small streamlet in secondary forest with bamboo: among gravel and stones in a small pool, 5 May 2011, Fikáček and Zhao lgt.; 5 spec. (NMPC): same locality data, but with habitat data as follows: exposed pools along the road partly connected to the stream; sparsely to densely overgrown by grass. 


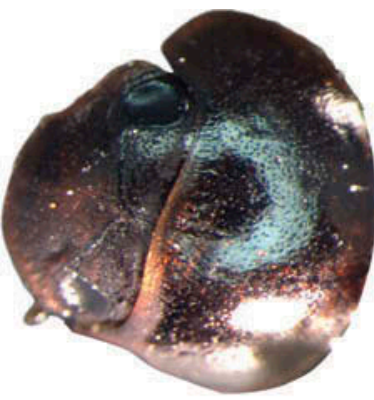

A
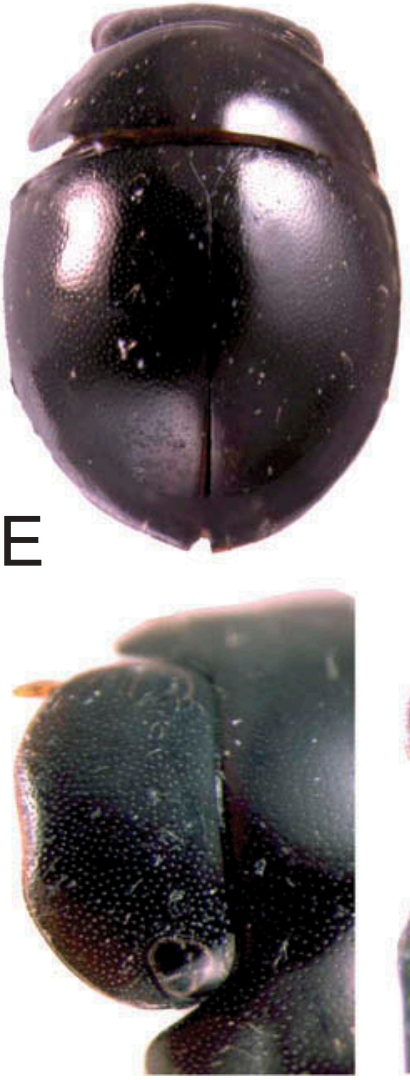

$\mathrm{H}$

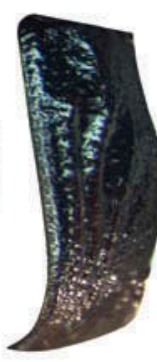

B

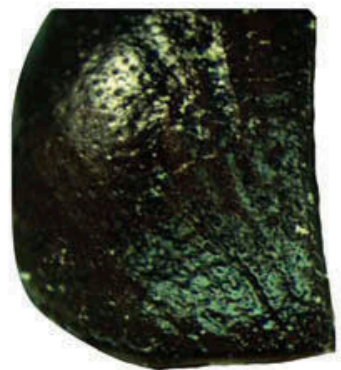

C
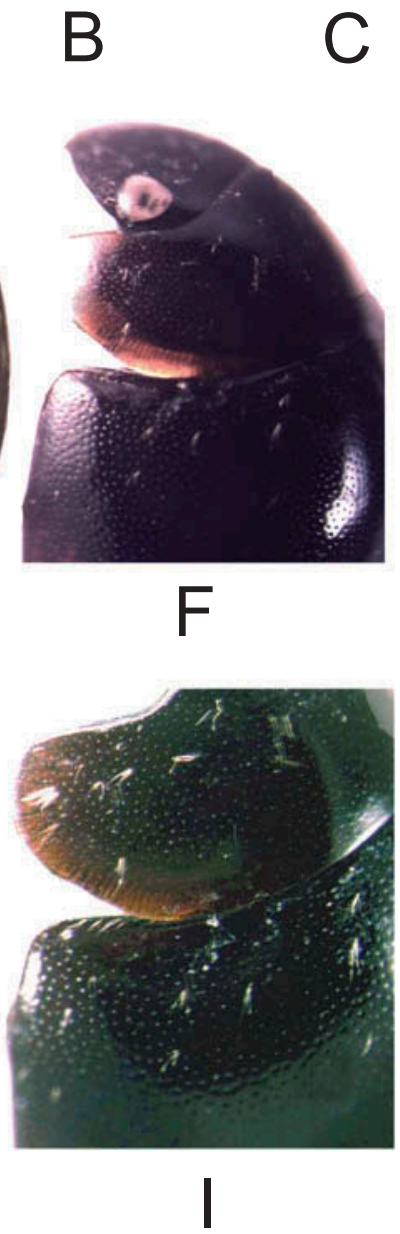

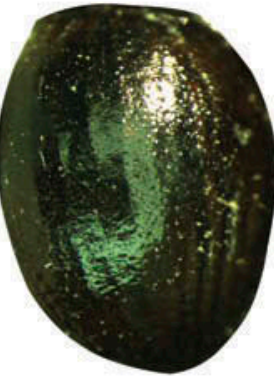

D
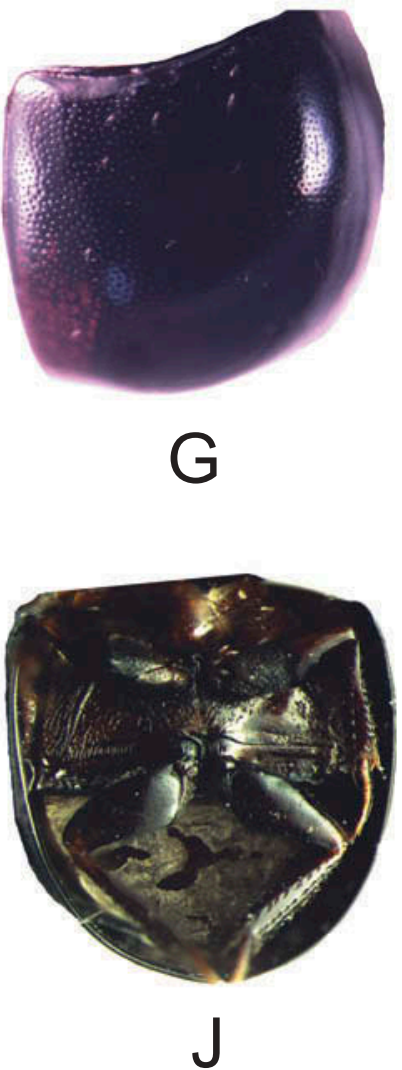

Figure 2. Amphiops caristripus Jia. (A) Head and pronotum; (B) elytra, lateral margin; (C) elytral apex; (D) elytra. Amphiops coelopunctatus sp. nov. (E) Habitus; (F) head, pronotum and elytra base, lateral view; $(\mathrm{G})$ elytra; $(\mathrm{H})$ head; (I) pronotum and elytral base; (J) metasternum and abdomen. 


\section{Diagnosis}

Dorsum glabrous, black. Anterior margin of clypeus broadly truncate; head with sparse punctation, all punctures of the same size; lateral portions of pronotum with punctation identical to those on head, punctures on median portion finer; elytra without serial punctures, ground punctation similar to head, lateral punctures somewhat coarser than those on inner parts. Systematic punctures on head, pronotum and elytra of the same size as ground punctures. Lateral margin continuously curved to posterior margin, (Figure 2F, I), hence posterolateral angle absent. Mesofemora very narrowly separated. Metaventrite without a transverse ridge anteriorly. Mesofemora densely pubescent on basal third, metafemora glabrous, only pubescent along anterior margin on basal half. Aedeagus with median lobe broad, triangular apically, broadly notched behind apex on each side, gonopore situated apically; parameres as long as median lobe, almost parallel-sided, rounded apically, distinctly curved medially on inner face.

\section{Description}

Form and colour. Body strongly convex, broadly oval. Length 3.55-3.65 mm (holotype $3.60 \mathrm{~mm}$ ), width $2.60-2.65 \mathrm{~mm}$ (holotype $2.65 \mathrm{~mm}$ ). Black, lateral margin of pronotum yellowish brown. Maxillary palpomeres, labial palpomeres, antennae, legs and ventrites yellowish brown, ventral surface of mesoventrite and metaventrite yellowish brown to dark brown. Antennal club dark.

Head. About $1.75 \times$ as wide as long. Glabrous, without microsculpture between punctures, with punctation consisting of single size of ground punctures mixed with some systematic punctures of the same size as ground punctures, intervals between punctures c.1.25-1.50 $\times$ the diameter of a puncture. Anterior margin of clypeus broadly truncate or slightly concave anteriorly. Frontoclypeal suture indistinct, sometimes undetectable. Mentum c. $0.75 \times$ as long as wide, with sparsely arranged systematic punctures, slightly emarginate anteriorly. Apical maxillary palpomere asymmetrical, longer than penultimate palpomere.

Thorax. Pronotum c. $2.25 \times$ as wide as long, median portion with finer and sparser punctures than those on head, lateral portion with coarser punctation consisting of single size of ground punctures intermixed with systematic punctures of the same size; intervals between punctures about c.1.5-1.7 $\times$ the diameter of a puncture mesally, c.1.2-1.4 $\times$ laterally. Posterolateral margin rounded, posterior angle unclear. Prosternum short, with a strong median carina. Scutellum longer than wide, with same punctures mesally as on pronotum. Elytra almost as high as long, ground punctures similar to head but somewhat coarser laterally, intervals between punctures c.1.3-1.5 $\times$ the diameter of a puncture mesally, c.1.1-1.2 $\times$ laterally; elytron with five series of setiferous punctures (systematic punctures) that are the same size as ground punctures, serial punctures absent. Mesoventrite gradually raised posteriorly to form a narrowly notched protuberance, mesocoxae very narrowly separated. Metaventrite slightly convex medially, without transverse carina anteriorly. Profemora and mesofemora densely pubescent on basal half, metafemora only pubescent anteriorly on 
basal half, with fine and sparse punctures beneath, without microsculpture between punctures.

Abdomen. Covered with hyaline mass. Visible part of first ventrite very short, without median carina, with marginal short and very fine setae anteriorly.

Aedeagus. Median lobe broad, triangular apically, broadly notched behind apex on each side, gonopore situated apically. Parameres as long as median lobe, almost parallel-sided, rounded apically, distinctly curved mesad on inner face. Phallobase slightly longer than parameres, abruptly narrowed medially (Figure 5B).

\section{Differential diagnosis}

The new species is close to A.coomani and A.globus based on the pronotum without distinct posterolateral corners, elytra without series of coarse punctures, head, pronotum and elytra with ground punctures of single size; metaventrite without a transverse carina anteriorly, and metafemora glabrous with fine punctures. It can be easily distinguished from these species by the dorsum with denser and coarser punctures, pronotum and elytra with systematic punctures of the same size as ground punctures, and median lobe of the aedeagus narrower, triangular apically, broadly notched behind apex on each side.

\section{Etymology}

The species name is a combination of Coelostoma, a genus of the hydrophilid tribe Coelostomatini, and the Latin punctatus. The name refers to the fact that the head, pronotum and elytral punctation of this new species are similar to the dorsal punctation of many Coelostoma species.

\section{Biology}

Aquatic. Part of type series was collected in an exposed pool connected to the stream and overgrown by grass, while the second part of the series was collected from the gravel on the side of a small streamlet shaded streamlet in the secondary forest c. $50 \mathrm{~m}$ from the exposed pool (Fikáček and Zhao, pers. comm.).

\section{Distribution}

China: Hainan.

\section{Amphiops mater Sharp, 1873}

(Figures $3 \mathrm{~A}-\mathrm{E}$, and $5 \mathrm{G}, \mathrm{H}$ )

Amphiops mater Sharp, 1873: 62 (specific rank confirmed by Balfour-Browne 1939: 304). - Type localities: Japan, Honshu (Hyogo), Kyushu (Nagasaki).

Amphiops pedestris Sharp, 1890: 354. - Type locality: Sri Lanka, Colombo N. Syn. Amphiops mater ssp. pedestris Sharp; Balfour-Browne, 1939: 304. 

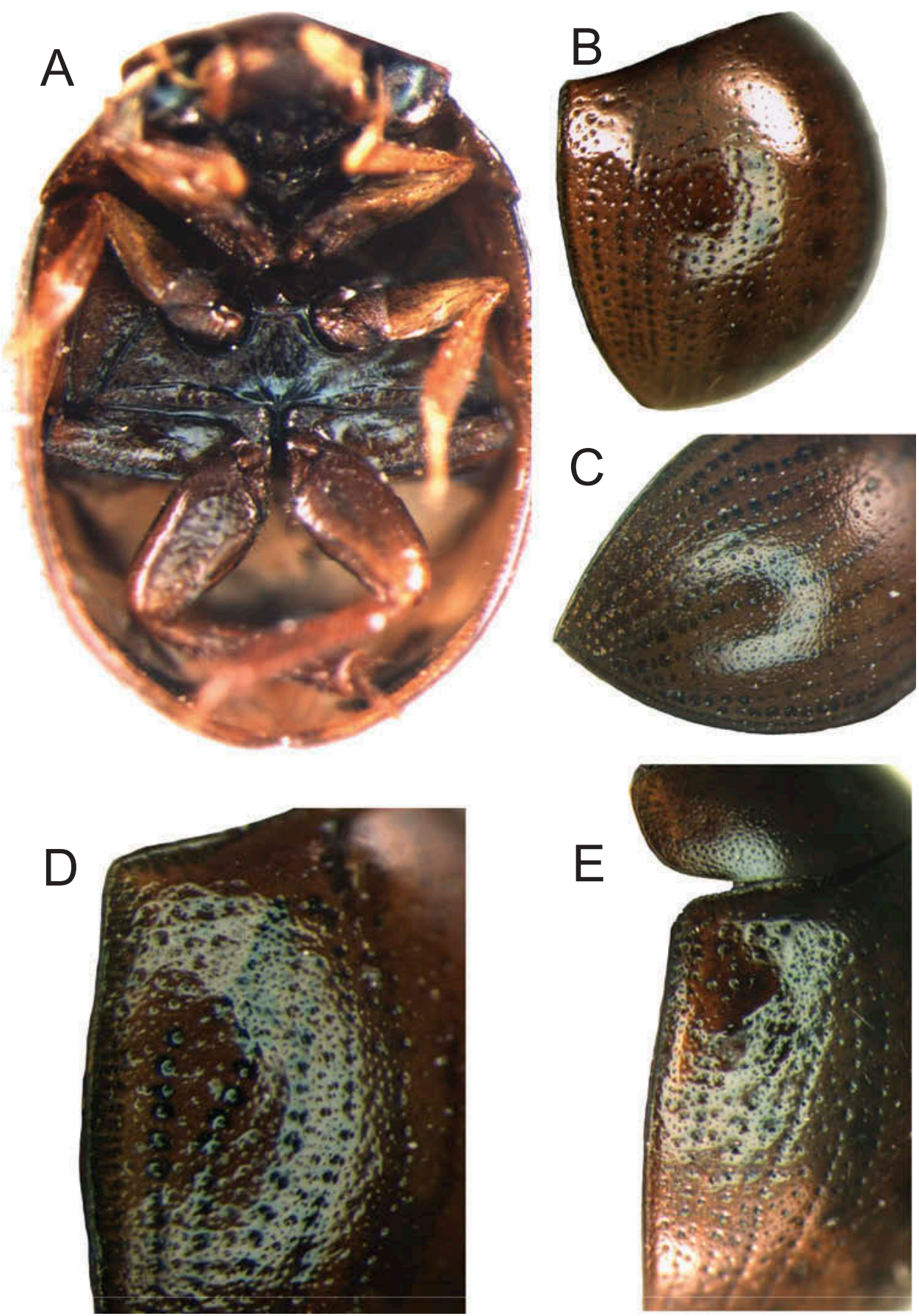

Figure 3. Amphiops mater Sharp. (A) Habitus, ventral view; (B) elytra (from Guangzhou); (C) elytral apex; (D, E) lateral portion of elytra. 
Amphiops annamita Régimbart, 1903: 62. - Type locality: Vietnam, Annam. N. Syn. Amphiops mater ssp. annamita Régimbart; Balfour-Browne, 1939: 304.

Amphiops gibbus var. mater Sharp; Zaitzev, 1908: 399.

Amphiops pedestris var. varians d'Orchymont, 1922: 629.

\section{Material examined}

Tianjin. 1 male (IZCAS: IOZ (E) 1381438), Tianjin, 2.5.22?; 1 spec., Peiping (Beijing), seriously damaged, with a label "A. pedestris"; Jiangsu: 1 male, Wuxi, with a label "A pedestris"; 2 spec., Suchow (Suzhou), with a label "A. pedestris"; Shanghai: Jiangwan Univerisity campus, 6 June 1956; 2 spec., Shanghai, 5 August 1950, with a label "Amphiops pedestris Rég." and another label "A. pedestris"; Zhejiang: 1 spec., Hangzhou, with a label "A. pedestris"; Jiangxi: 4 spec., Jiujiang, Duchang county, Linshan village, 15-20 July 2010, Yan Mei leg.; 12 spec., Jiulianshan Mountain., 20 April 2009, Fenglong Jia leg.; 2 spec., Yongxin county, 19 August 1974; 12 spec., Jingu county, 22 August 1974; 3 spec., Nanchang, 26 August 1963, Zhelong Pu leg., each with a label "A. pedestris"; 13 spec., Ji'an, 13 August 1974; 2 spec., Wuzhou, 16-18 August 1974, each with a label "A. pedestris"; Guangxi: 2 spec., Shiwandashan Forest park, 267 m, in light trap, 9 July 2011, Keqing Song leg.; 1 male, 1 unsexed spec., Yangshuo, 1985, in light trap; 14 spec., Nanning, 19 June 1977, Zhihe Huang leg., each with a label "A. pedestris"; 2 spec., Shangsi, 24 June 1977, Zhihe Huang leg.; 18 spec., Longlin, 22.v.1977, Zhihe Huang leg., each with a label "A. pedestris"; Guangdong: 2 spec., Canton, with a label "Amphiops pedestris varians Orchymont" and another label "Amphiops pedestris"; 1 male, 7 unsexed spec., Guangzhou, Kangle, iv.1957, Ping Lin leg.; 5 spec., Lianjiang, 25 September 1985, Wu Wu leg.; 42 spec., Xingning, Luofu, Tieshan, 1 July 2004, Fenglong Jia leg.; 15 spec., Zhuhai, Qi'ao island, 12 July 2005, Fenglong Jia leg.; 1 spec., Shaoguan, Yingde, 4 August 1962, Ping Lin leg.; 27 spec., Zhanjiang, Chikan, 25 September 1985, Zhihe Huang leg.; 3 spec., Lianjiang Shiling, 12 September 1985, Zhihe Huang leg.; 19 spec., Dinghu, 10 May 1994, Fenglong Jia leg.; 1 spec., Dinghushan, 1 June 1963, Dexiang Gu leg.; 3 spec., Dinghushan, 17 July 1964, Tongxu Peng leg.; 1 male, Shantou, 15 May 1964, Tongxu Peng leg.; 8 spec., Xuwen, 27 September 1985; 39 spec., Huaxian (Huadu), Dabuling, 26 August 1983, Zhihe Huang leg.; 1 spec., Xinyi, 7 June 1960, Zhelong Pu leg.; 1 spec., Lechang, 12 August 1962, Ping Lin leg.; 2 spec., Sihui, 1 November 1994, Fenglong Jia leg.; 15 spec., Heshan, 18 March 1994, Fenglong Jia leg.; 7 spec., Fengkai, Heishiding, 10 April 1985, Wu Wu leg.; 2 spec., Fengkai, Heishiding, 6 July 1986, Wu Wu leg.; 17 spec., Guangzhou, Sun Yat-sen Univerisity campus, July 1985; 2 spec., Guangzhou, Sun Yat-sen University campus, 15 April 1958, Yujia Hu leg.; 1 spec., Guangzhou, August 1938, Zhelong Pu leg.; 1 spec., Guangzhou, Shuzhugang, 3 May 1957, Zhelong Pu leg.; 1 spec., Guangzhou, Luogang, 20 April 1958, Zhelong Pu leg.; 5 spec., Guangzhou, June 1955, Chaoyang Li, Huifang Qi, Yongqiang Zhang and Lizhen Zeng leg.; 7 spec., Guangzhou, Shipai, 28 June 1955, Desheng Liu, Meizhen Mao, Pinzhen Jiang, Xiefang Tang, Zhenlun Xie, Qiyan Wang and Xuehai Luo leg.; 1 spec., Guangzhou, Henan (southern Pearl river), 1 April 1958; 1 spec., Guangzhou, Baiyunshan, 21 April 1958; 2 spec., with label "Guangzhou", August 1938, Zhelong Pu leg.; 1 spec., Dongguan, Chang'an town, 19 April 2004, Fenglong Jia leg.; 1 spec., Danxiashan Mountain, 26 August 2012, 
Fenglong Jia and Keqing Song leg.; 2 spec., Danxiashan Mountain, plant nursery; 3 spec., Danxiashan Mountain, Yangyuanshan, Huiyuanchi pool, 21 April 2012, Fenglong Jia and Junlei Liao leg.; 13 spec., Danxiashan Mountain, 16-20 May 2009, Fenglong Jia leg.; Fujian: 3 spec., Xiamen (with another label "Amor"); 1 spec., Xiamen (Amor), with a label "Amphiops mater Sh." and another label "A. pedestris"; Hainan: 1 spec., Sanya, 24 December 1963; 7 spec., Lingshui, Diaoluoshan Mountain., 25 November 1963, Jincai Bao leg.; 1 spec., no locality and date data; 1 spec., Jianfengling, 22 November 1983, Zhihe Huang leg.; Hunan: 1 male, Yizhang, 1941, Zhelong Pu leg.; 3 spec., Huaihua, 15 August1982, Zhihe Huang leg., each with a label "A. pedestris"; 2 spec., Nanyue (Hengshan Mountain), 4 September 1941, Zhelong Pu leg.; Yunnan: 25 spec., Hekou, 8 June 1977, Zhihe Huang leg.; 6 spec., Mengla, Wangguancun Nature Reserve, in light trap, 22 July 2011; Mengla Natural Reserve, 4-5 August 2007, Jiahui Li leg.; Sichuan: 2 spec., Dakang, 24 August 2001, Ling Zhao leg.; Guizhou: 7 spec., Guiyang, 15 July 1982, Zhihe Huang leg.; 1 spec., Fanjingshan, Huguosi temple, 14 August 2001, Hong Pang leg.; Hubei: 2 spec., Wuchang, June 1958, Jieyu Hu leg. ; 1 spec., without any locality and date data, with a label "Amphiops pedestris varians Orchymont”. VIETNAM: Tonkin, Hoa-Binh, A. de. Cooman leg.

\section{Note}

Balfour-Browne (1939) treated Amphiops pisiformis Fairmaire, 1884, Amphiops pedestris Sharp, 1890, Amphiops annamita Régimbart, 1903, and Amphiops sumatrensis Régimbart, 1903 as subspecies of A.mater based on the morphology of the aedeagus of the complex and the consideration of "well-defined distinctions on geographical distribution". The specimens in this study show that the ground punctures on the intervals vary in density and size. Some specimens have fewer, sparser ground punctures which are more or less regularly arranged apically, other specimens bear denser and more irregular ground punctures which differ more or less in size apically, and still other specimens have denser ground punctures apically that are irregularly arranged but are more or less similar in size. All of the three forms appear syntopically in the series from Yunnan, Guangxi, Guangdong, Jiangxi and Hunan. The two specimens I checked from Vietnam have the elytra very similar to the typical $A$. pedestris. Moreover, the aedeagi show that there is no difference among the three forms and there are many specimens with ground punctation intermediate between the above "subspecies". Another subspecies, A.mater pisiformis Fairmaire occurring in Indo-China, may also be conspecific with A.mater Sharp, considering its distribution.

d'Orchymont (1935) and Wu (1936) reported Amphiops annamita Régimbart from Guangdong (Danes Island), A.mater Sharp from Beijing, Fujian (Xiamen), Zhejiang (Hangzhou) and Hubei (Wuchang), and A.pedestris Sharp var. varians Orchymont from Guangdong. These data were used by later entomologists for discussion of the Chinese Amphiops. Gentili et al. (1995) and Hansen (1999) recorded them from China partly based on the Catalogue by d'Orchymont (1935) and Wu (1936). [Although A.annamita Régimbart and A.pedestris Sharp are recognized as subspecies of A.mater currently, Gentili et al. (1995) treated them as valid species without any explanation or justification for the change in rank.] Actually, A.mater Sharp is widely distributed from southern China north to Beijing. 


\section{Distribution}

China (Beijing, Fujian, Guangdong, Guangxi, Guizhou, Hainan, Hubei, Hunan, Jiangsu, Jiangxi, Shanghai, Sichuan, Tianjin, Yunnan, Zhejiang), Cambodia, India (Tamil Nadu), Indonesia (Sumatra), Japan, South Korea, Sri Lanka, Vietnam. New for Guangxi, Guizhou, Hainan, Hubei, Hunan, Jiangsu, Jiangxi, Sichuan, Tianjin, Yunnan.

Amphiops mirabilis Sharp, 1890

(Figures 4A-I, and 5C-F)

Amphiops mirabilis Sharp, 1890: 355 (specific rank confirmed by Balfour-Browne 1939: 307). - Type locality: Sri Lanka [“(Ceylon): Kandy”].

Amphiops yunnanensis $\mathrm{Pu}, 1963:$ 80. Syn. nov. - Type locality: China (Yunnan: Xiaomengyang).

\section{Type material examined}

Amphiops yunnanensis. HOLOTYPE: female (IZCAS: IOZ(E)220509), with two collection data "Xiao Mengyang, 850 m, 4 May 1974, Qiuzhou Liang leg." (transcript from Chinese), and another label with same data in Russian, with a red label "HOLOTYPE Amphiops yunnanensis, det. Pu Zhelong" (handwriting) and a label "Amphiops yunnanensis" (handwritten).

Amphiops mirabilis. Not examined.

\section{Additional material examined}

CHINA: Yunnan: 3 males, 12 unsexed spec., Mengla Natural Reserve, 4-5 May 2007, Jiahui Li leg.; 1 spec., Mengla, Mengban, 4-5 August 2007, Jiahui Li leg.; 2 spec., Mengla, Longmen village, 5 October 2010, trap in light; Guangdong: 3 spec., Gaoming, Yangmei town, 23-26 April 2006, Fenglong Jia leg.; 1 spec., Shenzhen, Paiyashan Mountain, 17 May 2012, Fenglong Jia and Junlei Liao leg.; 1 male, Guangzhou, Henan (southern Pearl river), 1 April 1958, with a label "A. pedestris"; 1 spec., Guangzhou, August 1938, Zhelong Pu leg.; Jiangsu: 1 spec., Changchow (Changzhou); Guangxi: 1 male., Liuzhou, Linbaping village, 15 October 1948, with a label "Amphiops \# 2, ડ̄”"; 1 spec., Longlin, 22 May 1977, Zhihe Huang leg.; 1 male, Shangsi, 24 June 1977, Zhihe Huang leg.; Hainan: 2 males, 4 unsexed spec., Jianfengling, 22 November 1983, Zhihe Huang leg.; 2 spec., Hainan island, 16 December 1957, Cuiying Li leg.; 2 spec., Wanning, 17 December 1957, Cuiying Li leg.

\section{Differential diagnosis}

Pronotum clearly with a posterolateral angle although strongly rounded (Figure 4D), without wrinkles and elytra without ridges. Elytra with clear large strial punctures and sparse finer small punctures (Figure 4B, E, G-I). Aedeagus with median lobe only slighter shorter than parameres, parameres widened apically (Figure $5 \mathrm{C}-\mathrm{F}$ ). 

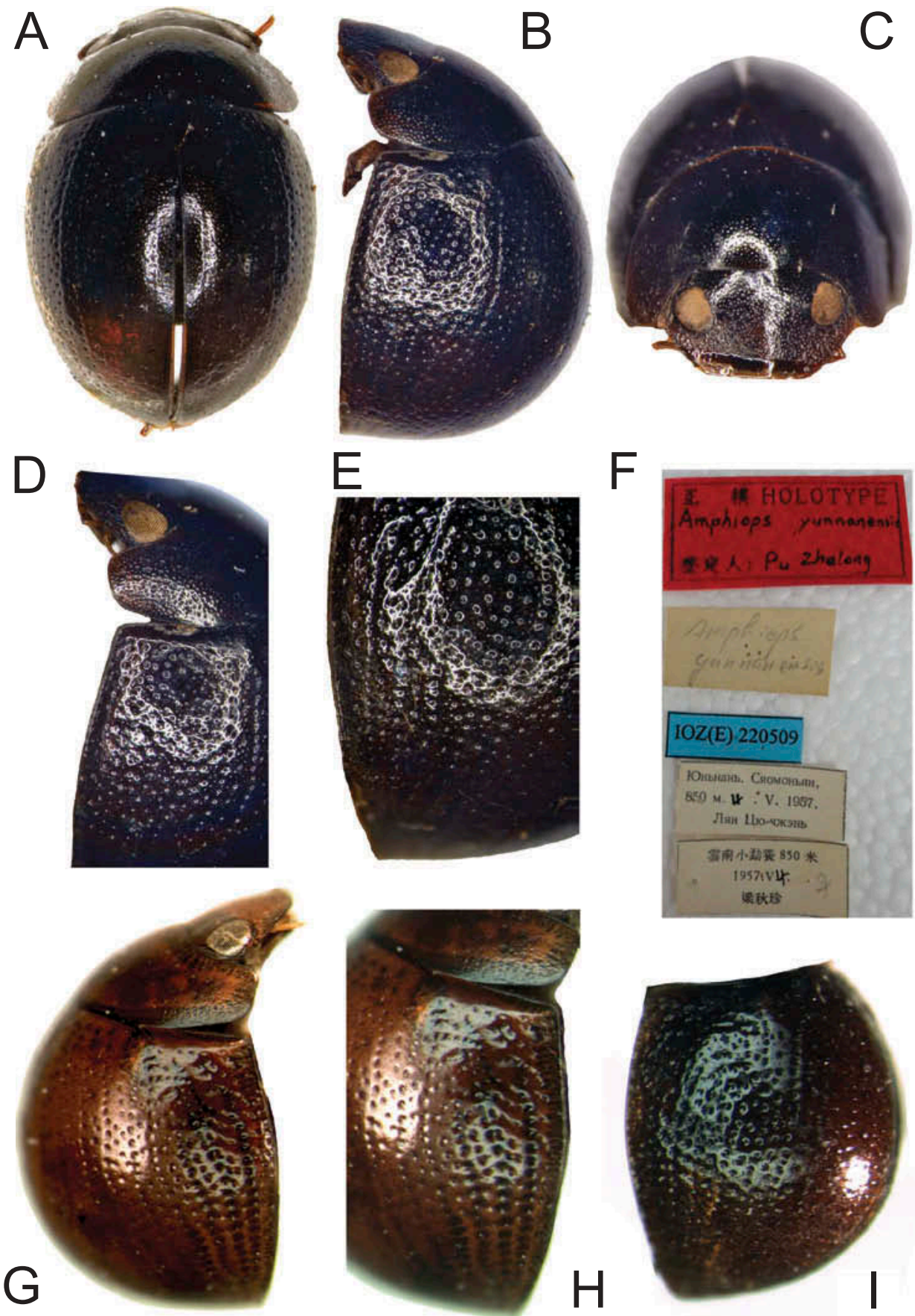

Figure 4. (A-F) Amphiops yunnanensis Pu. (A) Habitus (dorsal view); (B) habitus (ventral view); (C) head and pronotum; (D) lateral portion of pronotum and elytra; (E) elytra; (F) type data. (G-I) Amphiops mirabilis Sharp. (G) Habitus; (H) lateral portion of elytra; (I) elytra. 


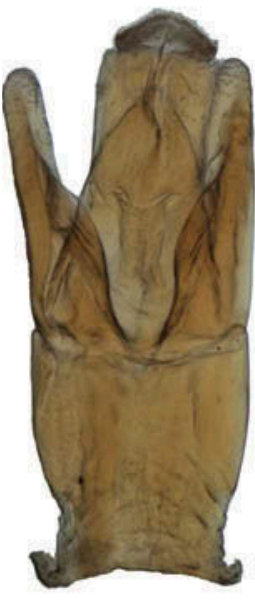

A

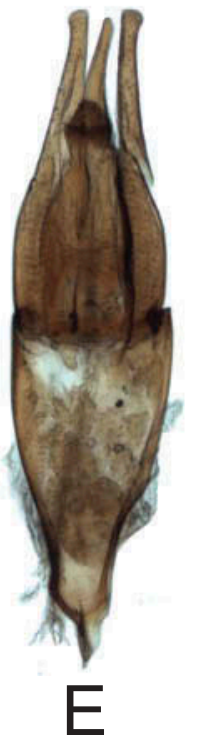

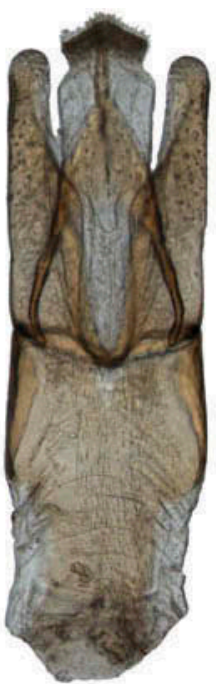

B
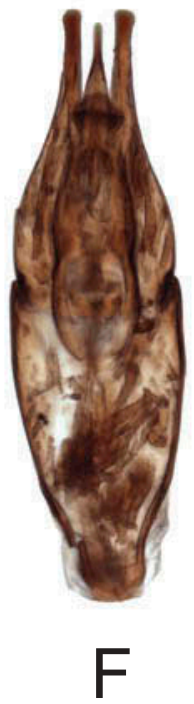
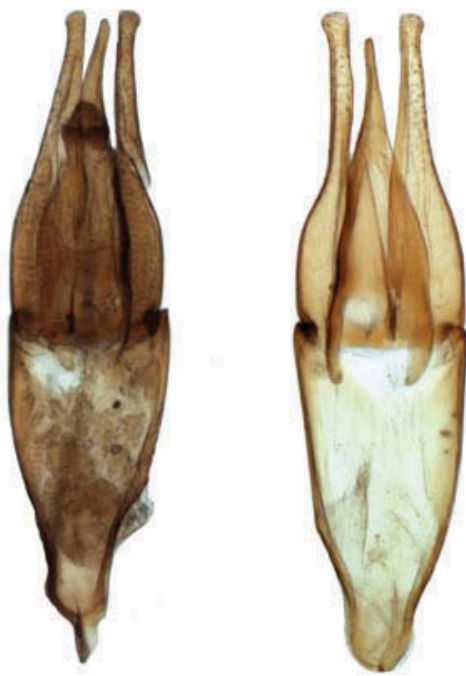

C

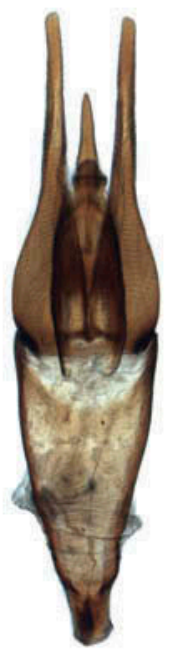

G

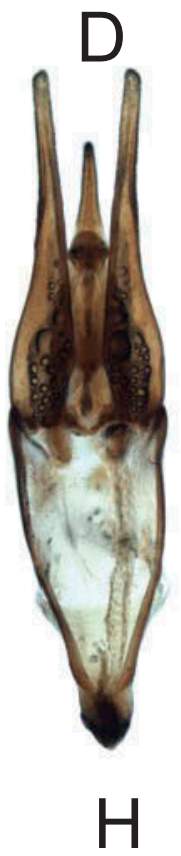

Figure 5. Aedeagi. (A) Amphiops coomani; (B) Amphiops coelopunctatus; (C-F Amphiops mirabilis, from (C) Guangzhou, (E) Hainan and (D, F) Yunnan; (G, H) Amphiops mater from $(\mathrm{G})$ Guangdong and $(\mathrm{H})$ Yunnan.

\section{Taxonomic note}

$\mathrm{Pu}$ (1963) described Amphiops yunnanensis based on a female. In the original description, he compared A.yunnanensis with A.annamita, A.mater and A.pedestris varians Orchymont, all now considered as synonyms of A.mater. It is probable that $\mathrm{Pu}$ (1963) 
did not know that A.mirabilis also occurs in China. I have been able to check the type in IZCAS. It is clear that A.yunnanensis is conspecific with A.mirabilis.

\section{Distribution}

China (Shandong, Jiangsu, Guangdong, Guangxi, Hainan, Yunnan), Myanmar, Indonesia (Java), Sri Lanka. New for Jiangsu, Guangdong, Guangxi, Hainan.

\section{Key to the Chinese species of Amphiops Erichson}

1. Pronotum without distinct posterior angle, posterolateral margin simply continuously rounded (Figures $1 \mathrm{~F}, 2 \mathrm{~F}, \mathrm{I})$. Elytra at most with a few large punctures forming 2-3 short lateral punctural series basally. Mesocoxae narrowly separated (Figure 2J). Metaventrite not truncate, without anterior transverse ridge. Metafemora smooth and finely punctate. 2 Pronotum with a posterolateral angle although strongly rounded (Figure 4D). Elytra with 10 clear large punctural striae. Mesocoxae broadly separated (Figure 3A). Metaventrite truncate anteriorly and with anterior transverse ridge (Figure 3A). Metafemora coarsely punctate, pubescent basally

2. Pronotum and elytra with strong punctures, intervals between punctures about $1.3-1.5 \times$ the diameter of a puncture, systematic punctures as large as ground punctures (Figures 2G, I). Median lobe of the aedeagus narrower, triangular apically, broadly notched behind apex on each side (Figure 5B).

A. coelopunctatus sp. nov.

Pronotum and elytra with extremely fine punctures, intervals between punctures at least c. $3.5 \times$ the diameter of a puncture, systematic punctures much coarser than ground punctures (Figure 1A, B, E). Median lobe of aedeagus broader, rounded apically, with a small notch behind apex on each side (Figure 5A)

A. coomani

3. Pronotum with some longitudinal wrinkles anteriorly (Figure 2A); elytra with weak ridges on inner portion (Figure 2C), clearly striate laterally and apically (Figure 2C), outer five intervals distinctly elevated (Figure 2B). A. caristripus Pronotum without wrinkles and elytra without ridges. 4

4. Elytra with coarser serial punctures and sparse finer small punctures (Figures 4B, E, G-I). Aedeagus with median lobe only slighter shorter than parameres, parameres widened apically (Figure 5C-F). A. mirabilis Elytra with smaller serial punctures and denser and coarser small punctures laterally (Figure 3B-E). Aedeagus with median lobe distinctly shorter than parameres, parameres not widened apically (Figure 5G, H)

A. mater

\section{Acknowledgements}

I am indebted to Dr Meiying Lin and Keqing Song (IZCAS) for taking photographs of Amphiops yunnanensis for me, to Mr Jun Chen and Jian Yao (both in IZCAS) for giving me 
the opportunity to check specimens in IZCAS, and to Miss Junlei Liao for her help with the photographs. Special thanks are given to Dr Martin Fikacek, Department of Entomology, National Museum, Czech Republic, and Dr Robert Angus, Department of Life Sciences (Entomology), The Natural History Museum, UK for their kind help with the English. The study was supported by the National Natural Science Foundation of China (31272266).

\section{References}

Balfour-Browne J. 1939. Contribution to the Study of the Palpicornia. - Part III. Ann Mag Nat Hist. 11:289-310.

Castelnau FL Laporte de. 1840. Histoire naturelle des Animaux articulés...Histoire naturelle des insects Coléoptères, 2 (Nécrophages-Trimères). 565 pp, 38 pls. Paris: P. Duménil.

d'Orchymont A. 1922. Zoological Results of the Abor Expedition. L. Coleoptera, X: Hydrophilidae. Rec Indian Mus. 8:623-629.

d'Orchymont A. 1926. Contribution à l'étude des Hydrophilides VI. Bull Ann Soc Entomol Belg. 66:201-248.

d'Orchymont A. 1935. Aquatic insects of China. Article XX. Catalogue of Chinese Palpicornia. (Order Coleoptera). Peking Nat Hist Bull. 9:185-225.

d'Orchymont A. 1936. Scientific results of the Vernay-Lang Kalahari Expedition, March to September, 1930. Ann Transv Mus. 17:109-116, 1 pl.

d'Orchymont A. 1941. Revision des Amphiops africains (Coleoptera Hydrophilidae). Bull Mus R d'Hist Nat Belg. 17:1-12.

Erichson WF. 1843. Beitrag zur Insecten-Fauna von Angola, in besondere Beziehung zur geographischen Verbreitung der Insecten in Afrika. Arch Naturgeschichte. 9:199-267.

Fairmaire L. 1884. Descriptions de deux Coléoptères nouveaux: Amphiops et Trachypholis. Ann Soc Entomol Fr. 6:xlvi-xlvii (= Bulletin de la Société entomologique de France (1884): 59-60).

Gentili E. 1995. Hydrophilidae: 3. The genus Laccobius Erichson in China and neighbouring areas (Coleoptera). In: Jäch MA, Ji, L, (editors.): Water Beetles of China, Vol. 1. Wien: ZoologischBotanische Gesellschaft in Österreich and Wiener Coleopterologenverein, p. 245-286.

Hansen M. 1999. World catalogue of insects. 2: Hydrophiloidea (s. str.) (Coleoptera). Stenstrup: Apollo Books; 416pp.

Hebauer A. 1998. An updated determination key to the African species of the genus Amphiops Erichson, 1843 (Coleoptera, Hydrophilidae). Acta Coleopterol. XIV:33-36.

Jäch MA, Easton ER. 1998. Water beetles of Macao (Coleoptera). In: Jäch MA, Ji, L. editors. Water beetles of China, Vol. 2. Wien: Zoologisch-Botanische Gesellschaft in Österreich and Wiener Coleopterologenverein; p. 43-50; 371pp.

Jia F. 1994. A new species of Amphiops Erichson in Fujian Province (Coleoptera: Hydrophilidae). Wuyi Sci J. 11:100-102. [in Chinese with English summary)].

Knisch A. 1924. Hydrophilidae. In: Junk W, Schenkling S, editors. Coleopterorum catalogus, Vol. 14, part 79. Berlin: W. Junk; 306 pp.

$\mathrm{Pu}$ C-L. 1963. Results of the zoologico-botanical expedition to southwest China, 1955-1957 (Coleoptera, Hydrophilidae). Acta Entomol Sin. 12:77-82. [in Chinese with English summary)].

Régimbart M. 1903. Contribution a la faune Indo-Chinoise. 19e mémoire. Ann Soc Entomol Fr. 72:52-64.

Sharp D. 1873. The water beetles of Japan. Trans Entomol Soc Lond. 1873:45-67.

Sharp D. 1890. On some aquatic Coleoptera from Ceylon. Trans Entomol Soc Lond. 1890:339-359.

Short AEZ, Fikáček M. 2011. World catalogue of the Hydrophiloidea (Coleoptera): additions and corrections II (2006-2010). Acta Entomol Mus Natl Pragae. 51:83-122. 
Short AEZ, Hebauer F. 2006. World Catalogue of Hydrophiloidea - additions and corrections, 1 (1999-2005) (Coleoptera). Koleopterologische Rundschau. 76:315-359.

Watts CHS. 1998. Revision of Australian Amphiops Erichson, Allocotocerus Kraatz and Regimbartia Zaitzev (Coleoptera: Hydrophilidae). Rec South Aust Mus. 30:93-106.

Wu CF. 1936/1937. Caltalogus insectorum sinensium. Vol. III. Peiping (Beijing): The Fan Memorial Institute of Biology; 1312 pp.

Zaitzev FA. 1908. Catalogue des Coléoptères aquatiques des familles Dryopidae, Georyssidae, Cyathoceridae, Heteroceridae et Hydrophilidae. Horae Soc Entomol Rossicae. $38: 283-420$. 